Research Article

\title{
Possible toxic effect of antihypertensive drug olmesartan on male reproductive system of rat
}

\author{
Srinivasa Jayachandra ${ }^{\mathrm{a}, *}$, AnnGie $\mathbf{N g}^{\mathrm{b}}$
}

${ }^{\mathrm{a}}$ Department of Physiology,

KMCT Medical College,

Kozhikode, Kerala, India

${ }^{\mathrm{b}}$ Ex-Monash student, School of

Sciences, Monash University, Malaysia

Received: 19 December 2012

Accepted: 20 January 2013

\section{*Correspondence to:}

Dr. Srinivasa Jayachandra,

Email:

jayachandra.srinivasa@gmail.com

\begin{abstract}
Background: To evaluate the possible toxic effect of a new angiotensin II receptor antagonist or blocker, olmesartan medoxomil, on the male reproductive system of rat.

Methods: Twelve Sprague Dawley rats, randomly divided into two groups: treated group $(n=6)$ and control group $(n=6)$. Olmesartan medoxomil $(5 \mathrm{mg} / \mathrm{kg} / \mathrm{dose})$ was fed to the treated group once daily for 28 days. Sperm motility, count and morphology and pituitary gonadal hormonal levels were assessed.

Results: Despite some fluctuations in sperm count, sperm motility, and concentration of testosterone, FSH and LH levels of treated group when compared to controls, the results were statistically insignificant.

Conclusions: It is therefore concluded that olmesartan medoxomil did not adversely affect the male reproductive health of treated rats.
\end{abstract}

Keywords: Olmesartan, Sperm count, Testosterone

\section{INTRODUCTION}

Hypertension is an important worldwide public-health challenge because of its high frequency and concomitant risks of cardiovascular and kidney disease. It has been identified as the leading risk factor for mortality and is ranked third as a cause of disability-adjusted life-years. ${ }^{1}$ The pharmacological management of hypertension includes: angiotensin-converting enzyme (ACE) inhibitors, angiotensin II receptor blockers (ARBs), beta blockers, diuretics, calcium channel blockers. Angiotensin II receptor blockers works on the same processes that ACE inhibitors do without producing cough as a side-effect. ${ }^{2}$ They block the AT1 receptors, while allowing angiotensin to still act on AT2 receptors. ${ }^{3}$ Olmesartan medoxomil (OM) is 2,3-dihydroxy-2butenyl4-(1-hydroxy-1-methylethyl)-2-propyl-1-[p-(o1H-tetrazol-5-ylphenyl)benzyl]imidazole-5-cardoxylate, cyclic 2,3-carbonate; C29H30N6O6. It is administered orally, and absorption occurs at the gastrointestinal tract. The drug undergoes ester hydrolysis and is converted to its active form, olmesartan. Only $1 \%$ of the dose is available for use, $99 \%$ is bound to plasma proteins. Excretion through faeces $(60 \%)$ and kidneys and mean bioavailability in healthy adults were $29 \%$. Duration of effect is dose dependent. Repeated studies show its high efficacy and superiority over drugs from other classes as well as those from its own class (e.g. losartan, valsartan, irbesartan and candesartan). ${ }^{4,5}$ This study aimed to evaluate the possible toxic effect of a new angiotensin II receptor antagonist or blocker, olmesartan medoxomil, on the male reproductive system of rat.

\section{METHODS}

\section{Experimental animals and grouping}

Twelve Sprague-Dawley rats were purchased from University Malaysia and were housed in the Monash University Malaysia animal house. The rats were maintained on normal diets under standard temperature $\left(22-25^{\circ} \mathrm{C}\right), 12 / 12-\mathrm{hr}$ light/dark cycle, ventilation, and hygienic conditions. Prior approval of local animal ethics committee was obtained. The twelve rats were divided into two groups - six rats for control (C) and six rats for treated $(\mathrm{T})$. Olmesartan medoxomil (Olmetec ${ }^{\circledR}$, Pfizer) was pounded from tablet form into powder, and one dose was mixed with one food pellet. This was prepared by first grinding the food pellet and then mixing it with one dose of olmesartan medoxomil. The dosage of Olmesartan used was $5 \mathrm{mg} / \mathrm{kg}$. $5 \mathrm{mg} / \mathrm{kg}$ was chosen as it was considered the high-end dose of the drug. ${ }^{6}$ The treatment period was 28 days, which was according to the EPA guidelines on toxicity studies, after which the rats 
were sacrificed. The weight of the rats before the start of the experiment ranged between $177.3 \mathrm{~g}$ and $219.5 \mathrm{~g}$. This averaged about $200 \mathrm{~g}$ each, and was used to calculate the dosage of Olmetec ${ }^{\circledR}$ to be mixed with the rat pellets. Rats under treatment were allowed to finish the one pellet which contained the single daily dose before being fed the rest of its food because this allowed the fasted rat to finish up the dose as fast as it can even though the drugged food pellet may taste slightly bitter. Olmesartan medoxomil was administered without regard to food intake as food doesn't affect the bioavailability of the drug. ${ }^{7}$

\section{Epididymal sperm count and sperm motility}

The rats were sacrificed under sodium pentobarbital anesthesia and laparotomy was conducted to expose the reproductive system. The latter was removed and placed in phosphate buffered saline, and the epididymis was separated. Testes and Epididymis from each animal were removed and weighed in an electronic balance. The sperm suspension was prepared by mincing the epididymis in $1 \mathrm{ml}$ of phosphate buffered saline ( $\mathrm{pH} 7.2)$. Then, the suspension was filtered through $80 \mu \mathrm{m}$ nylon mesh to remove the tissue fragments. An aliquot $(0.05$ $\mathrm{ml})$ from the sperm suspension $(1 \mathrm{ml})$ was diluted with 1:40 phosphate buffered saline and mixed thoroughly. After discharging a few drops, a sample of the diluted sperm suspension was introduced into a Neubauer's improved counting chamber. The sperms present in 8 squares except in the erythrocyte area were counted, and then the total count was multiplied by $5 \times 104$ to obtain the number of sperms per epididymis. A minimum of 100 sperms were observed for motility and percentage motile sperms was recorded for each animal. ${ }^{8,9}$

\section{Sperm morphology assay}

A part of sperm suspension was used for preparing smears to evaluate the sperm shape abnormalities. One drop of $1 \%$ eosin $\mathrm{Y}$ was added to the suspension and kept for $30 \mathrm{~min}$ and smears were prepared on clean glass slides and air-dried. For each animal, 200 sperms were examined microscopically at $400 \times$ magnification. The sperms presenting the defects in shape and structure of either head or tail or both were considered as abnormal and the data were presented as percentage incidence of total abnormalities. 9,10

The immunoassay kits were obtained from Teco Diagnostics, USA and hormonal assay were performed according to the manufacture's specifications. Blood was collected from each animal from heart by using heparinized syringe (23 gauge needle). Plasma samples were separated by centrifugation frozen and stored at $20^{\circ} \mathrm{C}$ until all the samples had been collected for the determination of Plasma Testosterone, Plasma follicle stimulating hormone (FSH) and Plasma luteinizing hormone (LH).
Values are expressed as the mean \pm Standard deviation. Data were analyzed statistically by the Student's t test. Pvalue $<0.05$ was considered significant.

\section{RESULTS}

The present study was aimed to evaluate the reproductive toxic effect of olmesartan on sperm count, motility, morphology and hormone levels of treated rats.

\section{Effect of olmesartan on body weight, testis weight and epididymis weight}

The mean body weight of treated and control rats did not vary much after 28 days of treatment. The standard deviation for the treated rats post-treatment were higher, although statistically $(p=0.78)$ the weight difference between the two groups were insignificant (Table 1).

Table 1: Mean body weight between treated and control rats.

\begin{tabular}{|c|c|c|}
\hline \multicolumn{3}{|c|}{ Mean body weight (g) } \\
\hline & $\begin{array}{l}\text { Before } \\
\text { treatment }\end{array}$ & $\begin{array}{l}\text { After } \\
\text { treatment }\end{array}$ \\
\hline Control & $198.22 \pm 14.49$ & $210.92 \pm 13.60$ \\
\hline $\begin{array}{l}\text { Treated group } \\
\text { (5mg/kg body } \\
\text { weight) }\end{array}$ & $200.33 \pm 18.33$ & $215.57 \pm 18.55$ \\
\hline t Stat & \multicolumn{2}{|c|}{$-0.28(\mathrm{t}$ Stat $<\mathrm{t}$ Critical $)$} \\
\hline$p$ value & \multicolumn{2}{|c|}{0.78} \\
\hline
\end{tabular}

Table 2: Mean testis and epididymis weight between treated and control rats.

\begin{tabular}{|c|c|c|}
\hline & $\begin{array}{l}\text { Mean testis } \\
\text { weight (g) }\end{array}$ & $\begin{array}{l}\text { Mean epididymis } \\
\text { weight (g) }\end{array}$ \\
\hline Control & $1.46 \pm 0.14$ & $0.67 \pm 0.139$ \\
\hline $\begin{array}{l}\text { Treated } \\
\text { (5mg/kg body } \\
\text { weight) }\end{array}$ & $1.42 \pm 0.19$ & $0.66 \pm 0.143$ \\
\hline t Stat & $\begin{array}{l}0.41(\mathrm{t} \text { Stat }<\mathrm{t} \\
\text { Critical) }\end{array}$ & $\begin{array}{l}0.36(\mathrm{t} \text { Stat }<\mathrm{t} \\
\text { Critical) }\end{array}$ \\
\hline$p$ value & 0.69 & 0.73 \\
\hline
\end{tabular}

As evident from table 2, the mean weight for testis of the control and treated groups were similar, as is the epididymis weight for the control and treated groups. However, the $\mathrm{t}-\mathrm{Stat}$ and $\mathrm{P}$ values showed that the results were not insignificant.

\section{Statistical analysis}




\section{Effect of olmesartan on sperm count, motility and morphology}

Mean sperm count for treated rats were slightly higher than that of the control rats as shown in Table 3. Due to the large $\mathrm{P}$ value $(p=45)$, this result was not significant. Mean sperm motility between both was statistically insignificant.

Table 3: Mean sperm count and motility between treated and control groups.

\begin{tabular}{|lll|}
\hline Control & $\begin{array}{l}\text { Mean sperm } \\
\text { count }(\times \mathbf{1 0} \mathbf{5} / \mathbf{m l})\end{array}$ & $\begin{array}{l}\text { Mean sperm } \\
\text { motility }(\%)\end{array}$ \\
\hline Treated & $23.31 \pm 2.90$ & $32 \pm 12.26$ \\
\hline t Stat & $\begin{array}{l}25.35 \pm 2.70 \\
\text { Critical })\end{array}$ & $32 \pm 11.72$ \\
\hline $\boldsymbol{p}$ value & 0.45 & $\begin{array}{l}0(\mathrm{t} \text { Stat }<\mathrm{t} \\
\text { Critical })\end{array}$ \\
\hline
\end{tabular}

${ }^{*} p<0.05$ considered to be statistically significant. Values are Mean $\pm S D$.
The morphology of sperm obtained from epididymis of control and treated rats were observed and of the 200 observed from each specimen, both groups had high numbers of normal sperm. As shown in Figure 1 and table 4 , the difference between the two groups in each morphology category were slight. There was no twotailed sperm seen in either group.

\section{Effect of olmesartan on hormonal levels}

Hormone concentrations of the rats were all statistically insignificant. Treated rats had a higher mean testosterone concentration. Whereas mean FSH concentration in control and treated rats were similar, at $5.06 \mathrm{mIU} / \mathrm{ml}$ and $5.83 \mathrm{mIU} / \mathrm{ml}$ respectively. LH concentration was also similar between the two groups, with the treated group having a slightly lower mean $(5.92 \mathrm{mIU} / \mathrm{ml}$ vs. 6.11 $\mathrm{mIU} / \mathrm{ml}$ ) (Table 5).

Table 4: Mean sperm morphology between control and treated groups.

\begin{tabular}{|lllllll|l|}
\hline & \multicolumn{6}{c}{ Mean sperm morphology $(\%)$} \\
\hline Control & $89.33 \pm 3.62$ & B & C & D & E & F \\
\hline Treated & $90.5 \pm \pm 3.70$ & $2.5 \pm 1.05$ & $4.58 \pm 1.99$ & $0.75 \pm 0.94$ & $2.75 \pm 1.51$ & 0 & \\
\hline
\end{tabular}

${ }^{*} p<0.05$ considered to be statistically significant. (A are normal, B lack a hook, $C$ have a banana-like shape, D are amorphous, $E$ are folded on themselves and $F$ are double-tailed).

Values are Mean $\pm S D$.

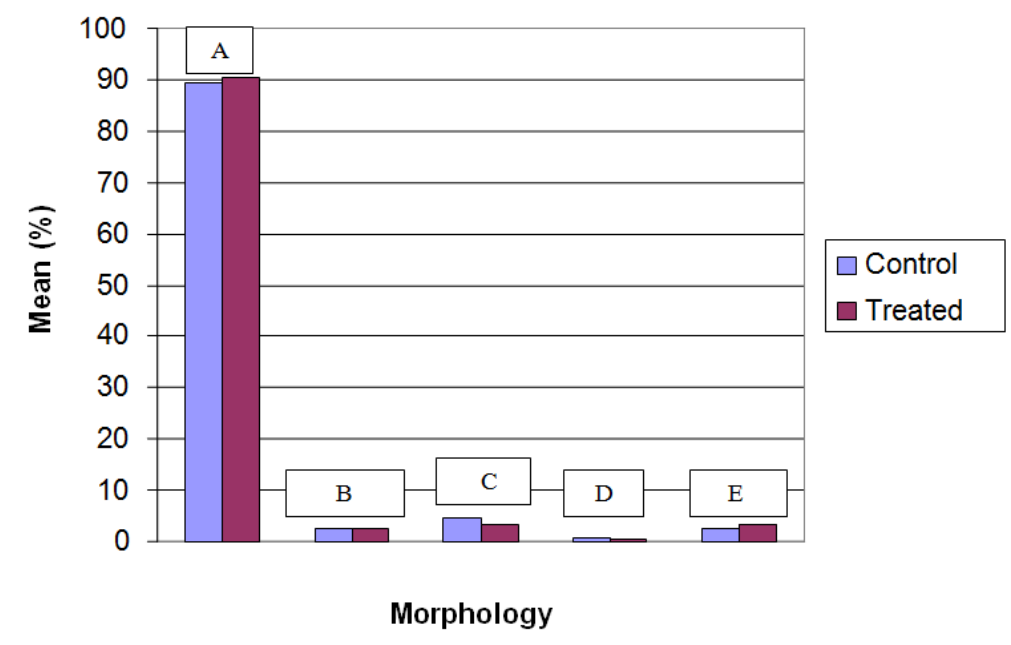

Figure 1: Mean sperm morphology. According to categories in control and treated rats. Sperms in A are Normal, B Lack a Hook, C Have a Banana-Like Shape, D are Amorphous, E are folded on themselves and F are Double-

Tailed. 
Table 5: Mean hormone concentration between treated and control groups.

\begin{tabular}{|llll|}
\hline \multicolumn{4}{|c|}{ Concentration of hormones } \\
\hline Control & $0.44 \pm 0.95$ & FSH $(\mathbf{m I U} / \mathbf{m l})$ & LH $(\mathbf{m I U} / \mathbf{m l})$ \\
\hline Treated & $1.30 \pm 1.34$ & $5.06 \pm 1.67$ & $6.11 \pm 1.29$ \\
\hline t Stat & $-1.518(\mathrm{t}$ Stat $<\mathrm{t}$ Critical $)$ & $-0.77(\mathrm{t}$ Stat $<\mathrm{t}$ Critical $)$ & $0.30(\mathrm{t}$ Stat $<\mathrm{t}$ Critical $)$ \\
\hline $\boldsymbol{p}$ value & 0.182 & 0.47 & 0.77 \\
\hline \multicolumn{4}{|c|}{$* P<0.05$ considered to be statistically significant. Values are Mean $\pm S D}$. \\
\hline
\end{tabular}

\section{DISCUSSION}

Male Sprague-Dawley rats were randomly selected to two groups, one of which served as a control group and the other group was treated with olmesartan medoxomil at $5 \mathrm{mg} / \mathrm{kg}$ dose.

There was no significant difference $(p=0.78)$ in body weight between the control group and the treated group of rats where weight change is concerned. Even the comparison of testis weight and epididymis weight between the control and treated group showed insignificant effect of olmesartan $(p=0.69$ and $p=0.73$ respectively).

Weight changes may indicate physiological abnormalities in the function of certain organs or systems, which could further develop into serious health complications. Decrease in testicular mass is an index of reproductive toxicity and could indicate atrophic and degeneration of tissue. ${ }^{11}$ It was thus important that proper weight monitoring was done as one of the steps to ensure that the rats were in good health. This served to show also that patients undergoing olmesartan therapy will very unlikely experience drastic and unhealthy weight changes.

Sperm count was important to analyze the toxicity of the drug in study on the spermatozoa production in the gonads of the rats. Damage to cells involved in spermatogenesis or lowered sex hormones could be reasons behind changes in sperm production.

Rats in the control and treated groups had a mean sperm count of $23.31 \pm 4.90 \times 10^{5} / \mathrm{ml}$ and $25.35 \pm 2.70 \times 10^{5} / \mathrm{ml}$. Despite a higher sperm count in the treated group, the difference between the two groups was insignificant $(p=0.45)$ to draw a conclusion that the drug affects sperm numbers in rats.

Motility between rats of control and treated groups were similar $(32 \%)$, with a standard deviation of 14.26 and 11.71 to each group respectively. Clearly, sperm motility was not affected by the treatment of olmesartan.

Sperm quality is dependent on 3 variables of the sperm, the count, motility and morphology. While the increase in sperm numbers will essentially increase the chances of a sperm fertilizing an oocyte, this relation will not be of importance if sperm motility was low. It is important that the sperm is motile in a progressive manner to be able to move up the cervix and along the fallopian tube to eventually encounter and fuse with an oocyte. Low sperm motility is often attributed to chemical-induced testicular toxicity. ${ }^{11}$

Sperms of control and treated rats had high levels of normal morphology $(89.33 \pm 3.615 \%$ and $90.5 \pm 3.70 \%$ respectively). This relatively high level of normality seen in the treated rats showed no adverse effect of olmesartan on the normal production of sperm where morphology is concerned. Both groups showed the same order in the number of abnormal sperm according to types of abnormality - sperm with banana-like form, folded on itself, without a hook, amorphous and lastly doubletailed. No sperm of the last category was observed.

Sperm morphology influences the degree of its motility. The energy required for the sperm to be motile is generated in the axoneme, whereas the tail is required for the progressive movement of the sperm. Hence, abnormalities in the anatomy of the sperm will largely impair its movements. An individual's sperm morphology may also reveal the overall health of the testes since its production is within the testis. ${ }^{12}$

The close-level of normality in the treated and control groups showed that olmesartan does not affect the morphology of sperm. The overall sperm analysis showed that olmesartan did not adversely affect, if at all, the quality of sperm.

Testosterone levels in the treated rats were higher, on average as compared to control rats, but it was not significant.

Components of the renin-angiotensin system have been found in the seminal fluid and male reproductive organs, pointing to the possibility that angiotensin II found in the seminal plasma is produced in the male reproductive tract. Angiotensin receptors can be found on the male testes and epididymis. ${ }^{13}$ AT1 and AT2 receptors have been localized in the rat epididymis epithelium. The renin-angiotensin system inhibits Leydig cells via the AT1 receptors. When this occurs, testosterone production should be affected considering that Leydig cells are 
responsible for testosterone secretion. This did not show in this experiment, and neither did it show in another study where plasma testosterone was unaffected by valsartan, also an angiotensin II receptor blocker. ${ }^{14}$ As testosterone is required in the later stages of spermatogenesis, this could possibly be one of the factors behind a slightly high mean sperm count in the treated group. The comparative mean concentration of testosterone between the control and treated group also indicates that Leydig cells were not damaged or adversely affected by olmesartan.

FSH levels were slightly higher in the treated group than in the control group. This was, however, statistically insignificant $(p=0.47)$ and would require a larger sample size to test its accuracy. It has been proposed that FSH levels increase as a result of seminiferous tissue damage due to higher inhibin secretion. ${ }^{15}$ FSH is inversely proportional to spermatogonia population but the concentration of FSH is higher in the treated group, which also had a higher sperm count than the control group. While the values are not statistically significant, this could be due to a higher incidence of spermatogonia which do not mature to become spermatozoa in the treated group. Elevated FSH concentration could also point to germinal epithelial damage and can be linked severe oligospermia or azoospermia of bad prognosis. ${ }^{15}$

Mean LH was only slightly higher in the control group, compared to the treated group. This difference was insignificant $(p=77)$, statistically. LH is an important hormone as it stimulates Leydig cells to produce testosterone. From Table 5, the higher testosterone level in the treated group might have indicated that LH levels in the treated group were higher than the control too. This is, however, not the case. First of all, LH concentration of an individual cannot be determined with just a single test. Instead, it has to be done several times over a period of time as LH is secreted in bursts which vary from 30 minutes to 480 minutes. Secondly, it has a short half-life. Therefore, a single determination of LH can only be $50 \%$ accurate. $^{15}$

As testosterone is released with about 40 minutes of lag time following LH stimulation of Leydig cells. Testosterone levels should also not be determined merely by a single test. The range of time in which $\mathrm{LH}$ is released also means that testosterone is released periodically. The diurnal peak pattern of testosterone is also seen in some men, but not in the male population in general. High levels of LH may indicate hyperthyroidism or androgen resistance syndrome. ${ }^{15}$ Despite some fluctuations with the treated group in sperm count, testis weight and hormone levels, the difference could not be used to draw a conclusion on such effects as they were statistically insignificant.

\section{CONCLUSION}

After treating rats with $5 \mathrm{mg} / \mathrm{kg}$ per dose of olmesartan medoxomil for 28 days, no significant difference were seen between the control and treated rat groups in mean body weight, mean testis and epididymis weight, mean sperm count, mean sperm motility, mean sperm abnormalities, and mean concentration of testosterone, FSH and LH. Therefore, it is concluded that olmesartan medoxomil did not adversely affect the male reproductive health of treated rats. However, further studies are warranted to draw a definite conclusion.

\section{ACKNOWLEDGEMENTS}

The authors are grateful to the laboratory staffs of school of arts and sciences for their technical assistance.

Funding: This work was funded by the school of Arts and Sciences, Monash Malaysia

Competing interests: None declared

Ethical approval: The study was approved by the local animal ethics committee

\section{REFERENCES}

1. Manimunda SP, Sugunan AP, Benegal V, Balakrishna N, Rao MV, Pesala KS.. Association of hypertension with risk factors \& hypertension related behaviour among the aboriginal Nicobarese tribe living in Car Nicobar Island, India. Indian J Med Res 2011;133:287-93.

2. Contrera F, de la Parte MA, Cabrera J, Ospino N, Israili ZH, Velasco M. Role of angiotensin II AT1 receptor blockers in the treatment of arterial hypertension. Am J Ther 2003;10:401-8.

3. Schiffrin EL. Vascular and cardiac benefits of angiotensin receptor blockers. Am J Med 2002;11:409-18.

4. Whittaker A. A review of olmesartan medoxomil - a new angiotensin II receptor blocker. $\mathrm{Br} \mathrm{J}$ Cardiol 2005;12:125-9.

5. Redon J, Fabia MJ. Efficacy in angiotensin receptor blockade: a comparative review of data with olmesartan. J Renin Angiotensin Aldosterone Syst 2009;10:147-56.

6. Nangaku M, Miyata T, Sada T, Mizuno M, Inagi R, Ueda Y, et al. Anti-hypertensive agents inhibit in vivo the formation of advanced glycation end products and improve renal damage in type 2 diabetic nephropathy rat model. J Am Soc Nephrol 2003;14:1212-22.

7. Wehling M. Can the pharmacokinetic characteristics of olmesartan medoxomil contribute to the improvement of blood pressure control? Clin Ther 2004;26:21-7.

8. Shetty AJ, Narayana K, Bairy KL, Bhat P, D'Souza U. The effect of carbamazepine on sperm counts in Wistar rats--reflecting upon its mitogenic potential. Reprod Biol 2007;7:177-81. 
9. D'Souza UJ. Effect of tamoxifen on spermatogenesis and tubular morphology in rats. Asian $\mathrm{J}$ Androl 2004;6:223-6.

10. Amann RP. Evaluating testis function noninvasively: how epidemiologist-andrologist teams might better approach this task. Hum Reprod 2010;25:22-8.

11. Metwally SA, Hekma AA, Fawzy HM, Hamdy A. The Protective Effect of Linseed Oil Against Carbendazim Induced Testicular Toxicity in Rats. Eur J Sci Res 2011;49:208-24.

12. Carreira JT, Mingoti GZ, Rodrigues LH, Silva C, Perri SH, Koivisto MB. Impact of proximal cytoplasmic droplets on quality traits and in-vitro embryo production efficiency of cryopreserved bull spermatozoa. Acta Vet Scand 2012;54:1-7.

13. Leung PS, Sernia C. The renin-angiotensin system and male reproduction: new functions for old hormones. J Mol Endocrinol 2003;30:263-70.

14. Forgari R, Preti P, Derosa G, Marasi G, Zoppi A, Rinaldi A, Mugellini A. Effect of antihypertensive treatment with valsartan or atenolol on sexual activity and plasma testosterone in hypertensive men. Eur J Clin Pharmacol 2002;58:177-80.

15. Martin-du Pan R. Endocrine pathology: Effects on male fertility, 2003. Available at http://www.gfmer.ch/Books/Reproductive_health/En docrine_pathology.html. Accessed 27 August 2011.

doi: 10.5455/2319-2003.ijbcp20130116

Cite this article as: Jayachandra $\mathrm{S}, \mathrm{Ng}$ A. Possible toxic effect of antihypertensive drug olmesartan on male reproductive system of rat. Int $\mathrm{J}$ Basic Clin Pharmacol 2013;2:83-8. 